\title{
СУТОЧНЫЕ ПЕРЕМЕЩЕНИЯ БУРЫХ МЕДВЕДЕЙ (URSUS ARCTOS) НА СРЕДНЕМ СИХОТЭ-АЛИНЕ
}

\section{DAILY MOVEMENTS OF BROWN BEARS (URSUS ARCTOS) IN THE MIDDLE SIKHOTE-ALIN}

I. Seryodkin

Summary. The daily movements of 12 adult males, seven adult females, and one young male of brown bears (Ursus arctos) were assessed using radio- and GPS telemetry in the Middle Sikhote Alin in 1993-2011. The average daily linear distance of adult males was $3.13 \mathrm{~km}$, adult females $1.65 \mathrm{~km}$, and young male $-2.12 \mathrm{~km}$. The daily distance of males was significantly greater than that of females. In females, the rate of daily movements was more in summer than in spring and autumn. Two types of movements were distinguished: insignificant with feeding and transitions up to $19 \mathrm{~km}$ per day. Significant movements of bears were more typical for males, were observed in all seasons, and were associated with feeding behavior.

Keywords: daily linear distance, radiocollars, Sikhote-Alin Reserve, space use, telemetry.

\section{Ввемение}

D урый медведь (Ursus arctos) на Дальнем Востоке России играет заметную роль в экосистемах и имеет большое практическое значение для человека (Ревенко, 1993; Юдин, 1993; Серёдкин, 2007). Он является ценным охотничьим видом, нуждающемся в грамотном управлении его ресурсами. Для управления популяцией бурого медведя большое значение имеет знание экологии этого животного в разных частях ареала.

Одной из важнейших экологических характеристик популяции является использование пространства, в том числе перемещения животных (Dahle, Swenson, 2003; Rigg, 2005; Popescu et al., 2017). Интенсивное антропогенное освоение местообитаний медведей ведет к преобразованию условий их существования, что влечет за собой изменение перемещений животных (Smith, 2002; Fortin et al., 2016; Skuban et al., 2016). Метод телеметрии позволяет оценить этот малоизученный аспект экологии бурого медведя.

Перемещения бурых медведей на Дальнем Востоке России изучены недостаточно, так как программ, применяющих методы радиотелеметрии и спутникового
Серёдкин Иван Владимирович

К.б.н., в.н.С., Тихоокеанский институт географии ДВО

РАН (Владивосток)

seryodkinivan@inbox.ru

Аннотация. Суточные перемещения 12 взрослых самцов, семи взрослых самок и одного молодого самца бурых медведей (Ursus arctos) оценивали с помощью радио- и GPSтелеметрии на Среднем Сихотэ-Алине в 1993-2011 гг. Среднее линейное суточное смещение взрослых самцов составило 3,13 км, взрослых самок - 1,65 км и молодого самца - 2,12 км. Суточные смещения самцов оказались достоверно больше, чем у самок. У самок показатель суточных перемещений был больше летом по сравнению с весной и осенью. Выделялись два типа перемещений: незначительные с кормлением и переходы протяженностью до 19 км за сутки. Значительные перемещения медведей были более характерны для самцов, наблюдались во все сезоны и были связаны с пищевым поведением.

Ключевые слова: использование пространства, радиоошейники, Сихотэ-Алинский заповедник, суточное смещение, телеметрия.

слежения животных, было относительно не много (Серёдкин, 2014). Ранее суточные перемещения медведей изучали на п-ове Камчатка и о-ве Сахалин (Серёдкин и др., 2019; Серёдкин, 2020). Информация по данному вопросу для Сихотэ-Алиня публиковалась ранее только частично (Серёдкин и др., 2014), в настоящем сообщении она дополнена и выполнена на большем количестве меченых особей.

Целью данной работы являлось изучение суточных перемещений бурых медведей на Среднем Сихотэ-Алине. Исследование включало оценку протяженности и характеристику суточных перемещений медведей в течение года и отдельно по сезонам.

\section{Материал и методы}

Исследования проводили в 1993-2011 гг. на Среднем Сихотэ-Алине (в Сихотэ-Алинском заповеднике и в его окрестностях) на территории Приморского края

Сихотэ-Алинь является горной системой со средней высотой гор в районе исследования 600-800 м над уровнем моря (Ветренников, 1976). Благодаря ярко выраженному разнообразию климатических, высот- 
Таблица 1. Характеристика меченых бурых медведей и данные наблюдения за ними на Сихотэ-Алине

\begin{tabular}{|c|c|c|c|c|c|c|}
\hline $\begin{array}{l}\text { Номер } \\
\text { медве-дя }\end{array}$ & Пол & $\begin{array}{l}\text { Возраст во время } \\
\text { от-лова, год }\end{array}$ & Macca, кг & Дата отлова & $\begin{array}{l}\text { Дата окончания } \\
\text { наблюдения }\end{array}$ & $\begin{array}{l}\text { Число су-точных } \\
\text { смещений }\end{array}$ \\
\hline 1 & Самец & 9 & 240 & 05.07.1993 & 27.07.1995 & 8 \\
\hline 2 & Самец & 11 & 305 & 19.07.1993 & 15.09.1994 & 3 \\
\hline 3 & Самец & 3 & 143 & 03.09.1993 & 10.09.1994 & 58 \\
\hline 4 & Самец & 12 & 268 & 10.09.1993 & 10.06.1995 & 46 \\
\hline 5 & Самец & 16 & 363 & 19.05.1994 & 06.05.1995 & 9 \\
\hline 6 & Самец & 8 & 220 & 31.05 .1994 & 25.05.1995 & 9 \\
\hline 7 & Самка & 7 & 138 & 04.06.1994 & 09.07.1997 & 14 \\
\hline 8 & Самка & 9 & 161 & 13.06.1996 & 06.11 .1999 & 5 \\
\hline 9 & Самка & 4 & 95 & 29.05.1997 & 26.11 .1998 & 19 \\
\hline 10 & Самка & $15-17$ & 74 & 14.09.1999 & 28.09.1999 & 1 \\
\hline 11 & Самка & 8 & 141 & 17.09.1999 & 15.08 .2001 & 10 \\
\hline 12 & Самка & $15-17$ & 187 & 21.10 .1999 & 16.06 .2000 & 4 \\
\hline 13 & Самец & 8 & 204 & 23.10.1999 & 27.10.2001 & 2 \\
\hline 14 & Самка & 9 & 215 & 31.10 .1999 & 28.08 .2000 & 37 \\
\hline 15 & Самец & 8 & 204 & 31.10 .1999 & 15.05 .2001 & 28 \\
\hline 16 & Самец & 13 & 256 & 19.05 .2000 & 12.04 .2002 & 7 \\
\hline 17 & Самец & $16-17$ & 275 & 14.06 .2000 & 03.08 .2000 & 5 \\
\hline 18 & Самец & $11-14$ & 315 & 18.05.2001 & 03.04.2002 & 3 \\
\hline 19 & Самец & $8-10$ & 235 & 23.09.2011 & 26.10.2011 & 9 \\
\hline 20 & Самец & $6-7$ & 180 & 12.10.2011 & 18.11.2011 & 26 \\
\hline
\end{tabular}

ных и почвенных условий, а также своему положению на стыке различных биогеографических районов Азии, Сихотэ-Алинь характеризуется одним из наиболее высоких в России биологическим разнообразием видов и природных сообществ. В горах преобладают кедрово-широколиственные и темнохвойные леса, а на побережье моря - широколиственные леса. Главными лесообразователями являются сосна корейская (Pinus koraiensis), ель аянская (Picea ajanensis), пихта почкочешуйная (Abies nephrolepis), лиственница даурская (Larix dahurica), ясень маньчжурский (Fraxinus mandshurica) и дуб монгольский (Quercus mongolica).

Животных с целью мечения отлавливали лапозахватыающими ловушками Олдрича на лесных тропах и с использованием приманки. Данный способ отлова медведей распространен в мире (Jonkel, 1993) и успешно применялся в России (Серёдкин и др., 2005).

Медведей обездвиживали при помощи дистанционного инъектора Telinject (Германия). Для анестезии применяли золетил (Zoletil, Virbac, Франция; 50\% тилетамина гидрохлорид и 50\% золазепама гидрохлорид) в рекомендуемых дозах (Kreeger, 1996).
Медведей № 1-18 (табл. 1) оснастили УКВ-радиоошейниками моделей MOD-400 и MOD-500 (Telonics, Меса, Аризона, США), а № 19 и 20 - радиомаяками «Пульсар» (ЗАО «ЭС-ПАС», Москва, Россия), закрепленными на ошейниках.

Радиослежение медведей с УКВ-радиоошейниками осуществляли при помощи принимающего устройства, настраивающегося на индивидуальные частоты радиопередатчиков. Принимающее устройство состояло из радиоприемника системы TR-2 (Telonics, Meca, Аризона, США) и переносных направленных антенн. Определение местонахождений медведей посредством радиотелеметрии осуществляли с воздуха с использованием вертолетов Ми-2, Ми-8 и самолета Ан-2 и с земли при помощи триангуляции. В воздухе радиосигнал улавливали с расстояния до 40 км, с земли - до 10 км. Спутниковый ошейник «Пульсар» содержит встроенный приемник GPS, определяющий местонахождение меченого животного, и радиопередатчик, посылающий информацию с географическими координатами на спутники системы Argos. Со спутников информация с локациями животного передается на наземные станции и затем исследователю (Рожнов, Сальман, 2010; Seryodkin et al., 2014). 
Таблица 2. Суточные смещения бурого медведя на Сихотэ-Алине по сезонам

\begin{tabular}{|c|c|c|c|c|}
\hline Пол, возраст & $\begin{array}{l}\text { Число } \\
\text { замеров }\end{array}$ & $\begin{array}{l}\text { Среднее смещение } \\
\text { за сутки, км }\end{array}$ & $\begin{array}{l}\text { SD (стандартное } \\
\text { отклонение), км }\end{array}$ & $\begin{array}{l}\text { Максимальное значение, } \\
\text { км }\end{array}$ \\
\hline \multicolumn{5}{|l|}{ весна } \\
\hline Самцы, взрослые & 10 & 3,38 & 4,58 & 15,21 \\
\hline Самки, взрослые & 21 & 0,90 & 0,66 & 3,23 \\
\hline \multicolumn{5}{|l|}{ лето } \\
\hline Самцы, взрослые & 78 & 3,14 & 3,18 & 19,22 \\
\hline Самец, молодой & 54 & 2,05 & 1,50 & 5,94 \\
\hline Самки, взрослые & 55 & 2,21 & 1,98 & 10,98 \\
\hline \multicolumn{5}{|l|}{ осень } \\
\hline Самцы, взрослые & 67 & 3,07 & 3,01 & 17,47 \\
\hline Самки, взрослые & 14 & 0,58 & 0,60 & 2,00 \\
\hline
\end{tabular}

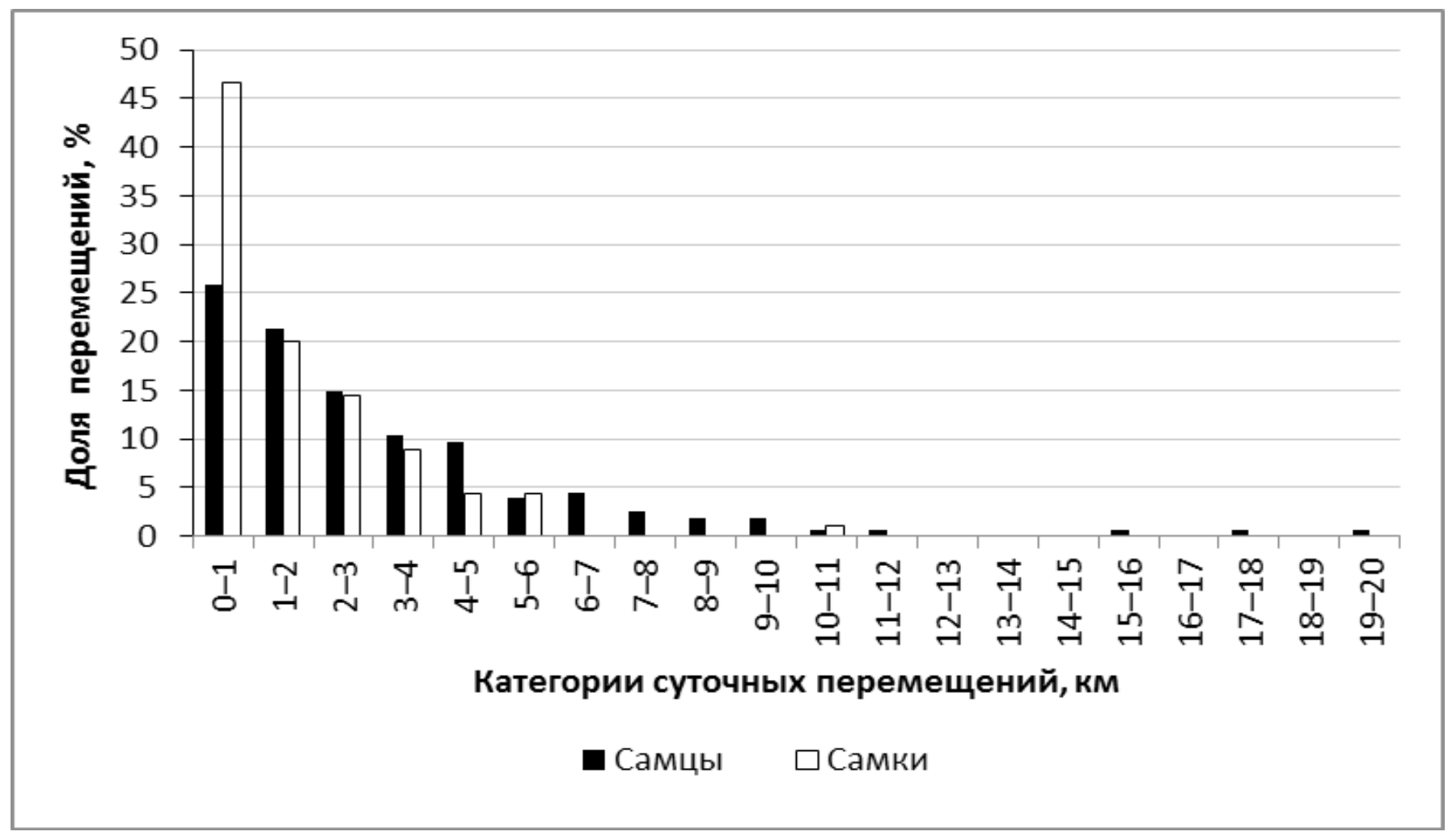

Рис. 1. Распределение суточных перемещений взрослых бурых медведей на Сихотэ-Алине по категориям их протяженности

В качестве характеристики суточных перемещений использовали суточное смещение - расстояние между локациями медведя, временной интервал между которыми составлял около суток (20-28 ч). Данные, полученные методом телеметрии, не точно отражают пройденное животными расстояние, так как не регистрируют весь путь, а оценивают дистанцию между двумя точками пеленгации. Суточные смещения меньше фактических расстояний, пройденных животными, тем не менее полученные данные позволяют оценить интенсивность перемещений медведей и закономерности использования пространства животными. 
В снежный период (апрель) для выяснения характера суточных перемещений животных и их связи с определенными типами поведения, производили тропления медведей. По следам бурых медведей пройдено 55 км.

Для сравнения выборок с показателями суточных перемещений медведей было обосновано применение непараметрического статистического критерия. Критерий Шапиро - Уилка $(p<0,05)$ и построение гистограмм не показали нормального распределения выборок, а критерий Бартлетта $(p<0,05)$ не выявил равенство их дисперсий. Сравнение выборок, требующих парного сравнения, провели U-критерием Манна Уитни. Различия в длине суточных смещений медведей для трех сезонов выявили критерием Крускала - Уоллиса ( $<<0,05)$, а дальнейшее попарное сравнение выполнили U-критерием Манна - Уитни с поправкой Бонферрони.

Расчеты статистических критериев проведены в программе R (ver. 3.5.2).

Сезоны (весна, лето, осень) выделены в соответствии с их обычными календарными сроками.

За весь период исследований была собрана информация по 303 суточным смещениям: 155-12 взрослых самцов, 90 - семи взрослых самок и 58 - молодого самца в возрасте 3-4 лет (табл. 1). Возраст животных определяли по числу линий прироста в зубном цементе передних премоляров, не несущих функциональную нагрузку (Клевезаль, 1988), а также по состоянию зубов и степени их истертости.

\section{Результаты}

Среднее суточное смещение для взрослых самцов составило 3,13 км (SD = 3,19 км) при разбросе значений от 0 до 19,22 км. Молодой самец за сутки смещался на расстояние от 0,07 до 5,94 км, в среднем на 2,12 км $(\mathrm{SD}=1,57$ км). У самок данный показатель составил 1,65 км (SD = 1,75 км), при максимуме 10,98 км. Между суточными перемещениями взрослых самцов и самок выявлены достоверные отличия ( $p<0,001)$. Также достоверно отличались перемещения взрослых самцов с таковыми молодого самца $(p<0,05)$.

Суточные перемещения взрослых самок были больше летом по сравнению с другими сезонами (табл. 2). Достоверные межсезонные отличия в длине суточных смещений среди половозрастных групп $(p<0,05)$ были выявлены у самок (весна-лето весна-осень и летоосень). Осенью суточные перемещения самцов были достоверно больше, чем у самок $(p<0,001)$.
Взрослые самцы, как и самки, за сутки чаще всего смещались на дистанцию не более 1 км, но в первой группе доля таких перемещений была $25,81 \%$, тогда как во второй - значительно больше - 46,67\% (рис. 1). Более протяженные суточные смещения (от 6 до 11 км) составили у самцов $14,19 \%$, тогда как у самок - только $1,1 \%$.

Незначительные суточные перемещения у наблюдавшихся медведей чередовались с дальними переходами (рис. 1). Так, самец № 1915 октября 2011 г за сутки сместился на 17,47 км, при этом он пересек главный водораздельный хребет данного региона - Сихотэ-Алинь. Кроме того, дальние переходы медведи совершали весной (например, самец № 4 в мае, 15,21 км) и летом (например, самец № 6 в августе, 19,22 км и самка № 14 в июне, 10,98 км).

Как показали тропления, существует два типа суточных перемещений. Для первого типа характерны незначительные переходы, обычно до 4 км в день. Такие перемещения характеризуются высоким коэффициентом извилистости пути и сопровождаются кормлением. Другой тип - целенаправленные переходы в определенном заданном направлении, без остановок на кормление.

\section{Обсужкение}

Среднегодовые суточные перемещения бурого медведя на Сихотэ-Алине по протяженности сопоставимы с таковыми в Европе (Huber, Roth, 1993; Pop et al., 2018). На Дальнем Востоке подобные исследования ранее проведены только по нескольким самкам на Восточной Камчатке и Восточном Сахалине, где суточные смещения составили 1,81 и 0,97 км соответственно.

Отмеченные нами существенные межсезонные различия в длине суточных перемещений бурых медведей характерны и для других регионов (Жиряков, Грачев, 1993; Завацкий, 1993; Clevenger et al., 1990; Серёдкин, 2020). Большая активность медведей летом (во время гона) по сравнению с осенью отмечалась, например, в Испании (Clevenger et al., 1990). В Якутии бурый медведь, оснащенный спутниковым радиомаяком, в июне проходил в сутки до 28 км (Николаев и др., 2012).

Протяженность суточных переходов часто связана с пищедобывательным поведением. Самцы № 19 и 20 во время всего слежения за ними (табл. 1) обитали в зоне кедрово-широколиственных лесов. В этот период они интенсивно кормились орехами кедровой сосны, накапливая жировые запасы для переживания зимнего периода. Незначительные суточные перемещения у этих медведей чередовались с дальними переходами. Первые были связаны с интенсивным кормлением орехами, 
а вторые - с переходами из одного речного бассейна в другой.

Значительные дневные переходы (до 20-35 км) медведи совершают в пред- и постберложный периоды (Завацкий, 1987, 1993; Жиряков, Грачев, 1993; Юдин, 1993). По свидетельству Юдина (1993) бурые медведи на юге Дальнего Востока в голодные годы в течение суток могут совершать переходы более чем на 50 км.

Длина суточного хода бурого медведя, не ложившегося в берлогу зимой, по пяти замерам, выполненным
Костоглодом (1979) в Сихотэ-Алинском заповеднике колебалась от 2 до 13 км. Отдельные участки дневного наследа (не вытропленные полностью) достигали 17, 19 и даже 32 км.

\section{Эак^ючение}

Благодаря использованию телеметрии удалось оценить суточные перемещения самцов и самок бурого медведя на Среднем Сихотэ-Алине. Исследование расширило знание экологии бурого медведя на Дальнем Востоке России, что важно для управления его популяциями.

\section{ЛИТЕРАТУРА}

1. Ветренников В. В. Геологическое строение Сихотэ-Алинского заповедника и Центрального Сихотэ-Алиня.- Владивосток: Дальневосточное книжное издательство, 1976. - 167 с.

2. Жиряков В.А., Грачев Ю. А. Бурый медведь. Центральная Азия и Казахстан // Медведи: бурый медведь, белый медведь, гималайский медведь.- М.: Наука, 1993.-С. 170-206.

3. Завацкий Б. П. Сроки залегания медведя в берлоги и их типы в енисейской тайге // Экология медведей. — Новосибирск: Наука, 1987.—C. 84-91.

4. Завацкий Б. П. Бурый медведь. Средняя Сибирь // Медведи: бурый медведь, белый медведь, гималайский медведь.— М.: Наука, 1993.—C. 294-275.

5. Клевезаль Г. А. Регистрирующие структуры млекопитающих в зоологических исследованиях.—М.: Наука, 1988. — 288 с.

6. Костоглод В. Е. Сравнительная экология бурого и белогрудого медведей на Среднем Сихотэ-Алине и влияние на них режима заповедности. Годовой отчет за 1978 г. - Терней: Сихотэ-Алинский государственный заповедник, 1979. — 20 с.

7. Николаев Е.А., Охлопков И. М., Кириллин Р. А., Мамаев Н. В. Наблюдения за перемещениями бурого медведя (Ursus arctos), меченного спутниковым радиомаяком, в Западной Якутии // Актуальные проблемы современной териологии: Тезисы докладов.— Новосибирск: 000 «Сибрегион Инфо», 2012. C. 157.

8. Ревенко И. А. Бурый медведь. Камчатка // Медведи: бурый медведь, белый медведь, гималайский медведь.— М.: Наука, 1993.—C. $380-403$.

9. Рожнов В.В., Сальман А. Л. Использование спутниковой системы Argos для наблюдения за животными на территории России // Земля из космоса: наиболее эффективные решения.— 2010.— № 7.—C. 42-47.

10. Серёдкин И. В. Роль бурого медведя в экосистемах Дальнего Востока России // Биоразнообразие и роль животных в экосистемах: Материалы IV Международной научной конференции. - Днепропетровск: Изд-во ДНУ, 2007.- С. 502-503.

11. Серёдкин И. В. Применение радиотелеметрии и спутникового слежения для изучения использования территории дикими животными на Дальнем Востоке России // Ареалы, миграции и другие перемещения диких животных. - Владивосток: 000 «Рея», 2014.— С. 292-299.

12. Серёдкин И. В. Суточные перемещения бурых медведей Ursus arctos на Камчатке и Сахалине // Вестник Томского государственного университета. Биология.— 2020.—№ 49.-С. 107-127.

13. Серёдкин И.В., Костыря А. В., Гудрич Д. М. Суточные и сезонные перемещения бурого медведя на Сихотэ-Алине // Вестник Тверского государственного университета. Серия «Биология и экология». - 2014.— № 4.—C. 233-240.

14. Серёдкин И.В., Костыря А. В., Гудрич Д. М., Шляер Б. О., Микелл Д. Г., Керли Л. Л., Квигли К. С., Квигли Х. Б. Отлов и иммобилизация гималайских и бурых медведей с целью радиомечения // Зоологический журнал.— 2005.— Т. 84, № 12.—C. 1508-1515.

15. Серёдкин И.В., Ликок В. Б., Пачковский Д., Петруненко Ю. К. Сезонные участки обитания и перемещения бурых медведей Ursus arctos в бассейне Курильского озера (Южная Камчатка) // Вестник Северо-Восточного научного центра ДВО РАН. — 2019. — № 3.— С. 80-90.

16. Юдин В. Г. Бурый медведь. Юг Дальнего Востока // Медведи: бурый медведь, белый медведь, гималайский медведь.— М.: Наука, 1993.—C. 348-380.

17. Clevenger A.P., Purroy F. J., Pelton M. R. Movement and activity patterns of a European brown bear in the Cantabrian Mountains, Spain // International Conference on Bear Research and Management. - 1990. - Vol. 8. - P. 205-211.

18. Dahle B., Swenson J. E. Home ranges in adult Scandinavian brown bears (Ursus arctos): effect of mass, sex, reproductive category, population density and habitat type // Journal of Zoology. - 2003. - Vol. 260.-P. 329-335.

19. Fortin J.K., Rode K. D., Hilderbrand G. V., Wilder J., Farley S., Jorgensen C., Marcot B. G. Impacts of human recreation on brown bears (Ursus arctos): A review and new management tool // PLoS One. - 2016. - Vol. 11(1). - e0141983.

20. Huber D., Roth H. U. Movements of European brown bears in Croatia // Acta Theriologica. — 1993. — Vol. 38, № 2. — P. 151-159.

21. Jonkel J.J. A manual for handling bears for managers and researchers. — Bozeman, MT: Interagency Grizzly Bear Study Team, Montana State University, 1993. — 175 p.

22. Kreeger T. J. Handbook of wildlife chemical immobilization. - Wyoming: International Wildlife Veterinary Sciences, Inc. Laramie, 1996. — $342 \mathrm{p}$.

23. Pop I.M., Bereczky L., Chiriac S., losif R., Nita A., Popescu V. D., Rozylowicz L. Movement ecology of brown bears (Ursus arctos) in the Romanian Eastern Carpathians // Nature Conservation. - 2018.- Vol. 26.-P. 15-31. 
24. Popescu V.D., Iosif R., Pop M. I., Chiriac S., Bouroș G., Furnas B. J. Integrating sign surveys and telemetry data for estimating brown bear (Ursus arctos) density in the Romanian Carpathians // Ecology and Evolution. — 2017._- Vol. 7(18)._P. 7134-7144.

25. Rigg R. A review of studies on brown bear (Ursus arctos) ecology in relation to home range, habitat selection, activity patterns, social organization, life histories and population dynamics // Oecologia Montana. - 2005.—Vol. 14. - P. 47-59.

26. Seryodkin I.V., Zaitsev V. A., Petrunenko Y.K. Pulsar satellite radio beacon application experience in the telemetry of brown bear (Ursus arctos L.) // Achievements in the Life Sciences. - 2014.—Vol. 8(1). - P. 43-46.

27. Skuban M., Findo S., Kajba M. Human impacts on bear feeding habits and habitat selection in the Polana Mountains, Slovakia // European Journal of Wildlife Research. - 2016. - Vol. 62(3).-P. 353-364.

28. Smith T. S. Effects of human activity on brown bear use of the Kulik River, Alaska // Ursus. — 2002. — Vol. 13. — P. 257-267.

(с) Серёдкин Иван Владимирович ( seryodkinivan@inbox.ru).

Журнал «Современная наука: актуальные проблемы теории и практики»

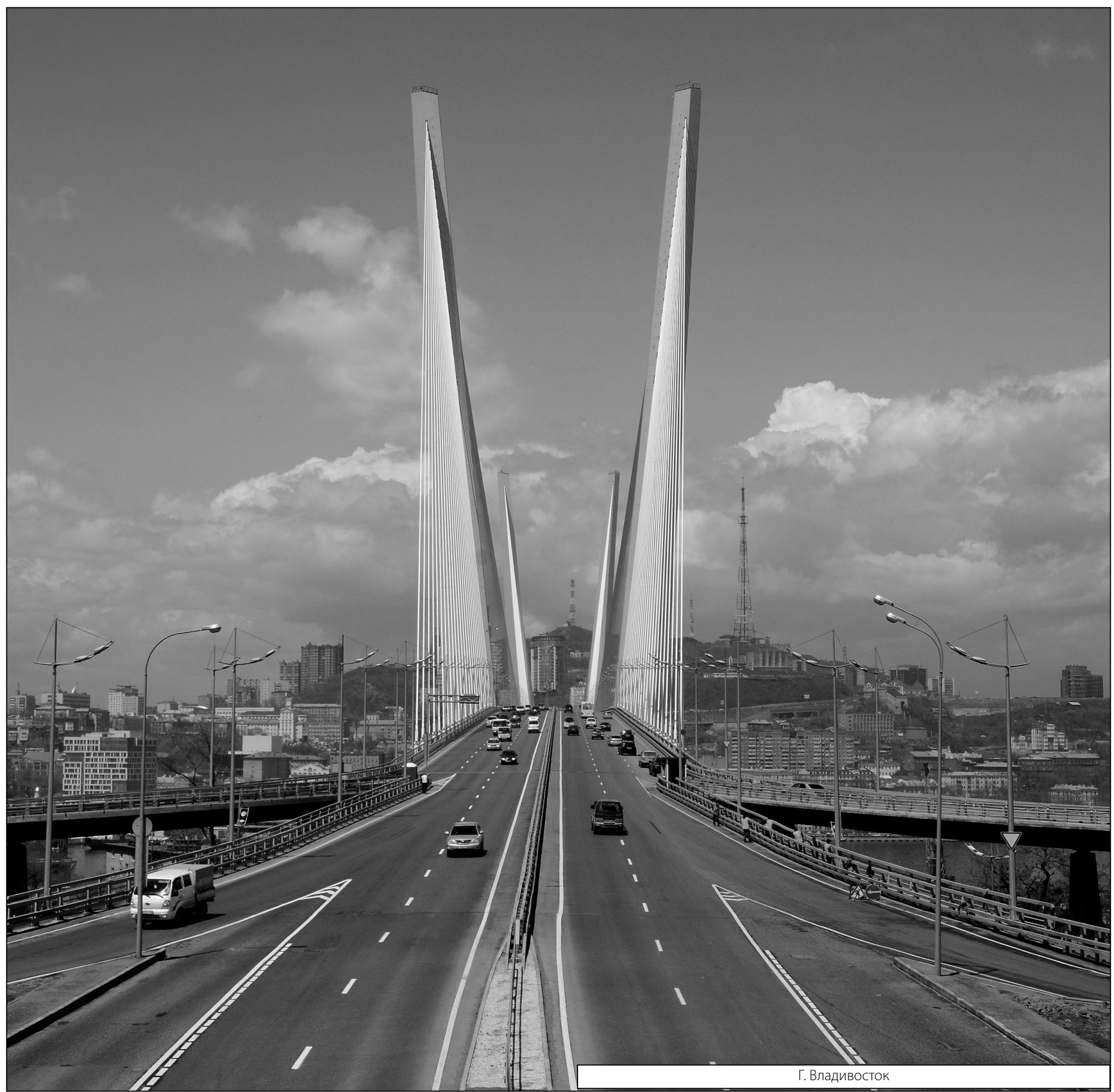

